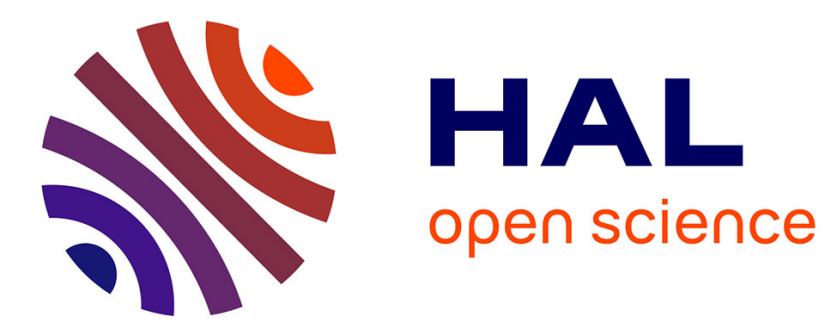

\title{
Low Cost Helicopter Training Simulator : A Software Case Study from the Brazilian Military Police
} Joice B. Mendes, Alexandre Carlos Brandao-Ramos, Felix Mora-Camino

\section{To cite this version:}

Joice B. Mendes, Alexandre Carlos Brandao-Ramos, Felix Mora-Camino. Low Cost Helicopter Training Simulator: A Software Case Study from the Brazilian Military Police. International Journal of Computer Science and Artificial Intelligence, 2014, pp 45-53. 10.5963/IJCSAI0402003 . hal01010400

\section{HAL Id: hal-01010400 \\ https://hal-enac.archives-ouvertes.fr/hal-01010400}

Submitted on 25 Sep 2014

HAL is a multi-disciplinary open access archive for the deposit and dissemination of scientific research documents, whether they are published or not. The documents may come from teaching and research institutions in France or abroad, or from public or private research centers.
L'archive ouverte pluridisciplinaire HAL, est destinée au dépôt et à la diffusion de documents scientifiques de niveau recherche, publiés ou non, émanant des établissements d'enseignement et de recherche français ou étrangers, des laboratoires publics ou privés. 


\title{
Low Cost Helicopter Training Simulator
}

\author{
A Software Case Study from the Brazilian Military Police \\ Joice B. Mendes ${ }^{1}$, Alexandre C. B. Ramos ${ }^{2}$, Felix Mora-Camino ${ }^{3}$ \\ ${ }^{1,2}$ Lab LMI, Federal University of Itajuba - UNIFEI, 1303, Av. BPS, 37500-903, MG, Brazil \\ ${ }^{3}$ Group Auto, French Civil Aviation University - ENAC, 7, Av. Édouard-Belin CS54005, 31055, Toulouse, France \\ 1.joice_unifei@yahoo.com.br; ${ }^{2}$ ramos@unifei.edu.br; ${ }^{3}$ felix.mora@enac.fr
}

\begin{abstract}
This work describes a computer based training system to assist the crew members to learn the ground school of helicopter AS350-B2, manufactured by HELIBRAS, a Brazilian helicopter company and widely used by the Armed Forces, Civil and Military Policies and by companies of executive transportation and load lifting. The training system consists of a 1:1 scale aircraft cabin simulator, a system software and a MS Flight Simulator interface. The project is in advanced phase of development and it already possesses positive declarations of interest from company training divisions and helicopter's operators. A case software used by Brazilian Military Police is presented.
\end{abstract}

Keywords- Helicopter Pilot Training; Computer Based Training; Hypermedia Based System; Flight Simulator

\section{INTRODUCTION}

This document reports studies using the integration of hardware and software to simulate the AS350-B2 helicopter flight dynamics and operations, as shown in Fig. 1, during normal flight situations. Computer algorithms are used so that the hardware and software can faithfully portray the helicopter instruments together with the external environment where it passes through.

The AS350-B2 helicopter is shown in Fig.1. The software implemented uses computer algorithms to simulate normal flight situations. The hardware together with software can faithfully portray the helicopter flight instruments and the external environment.

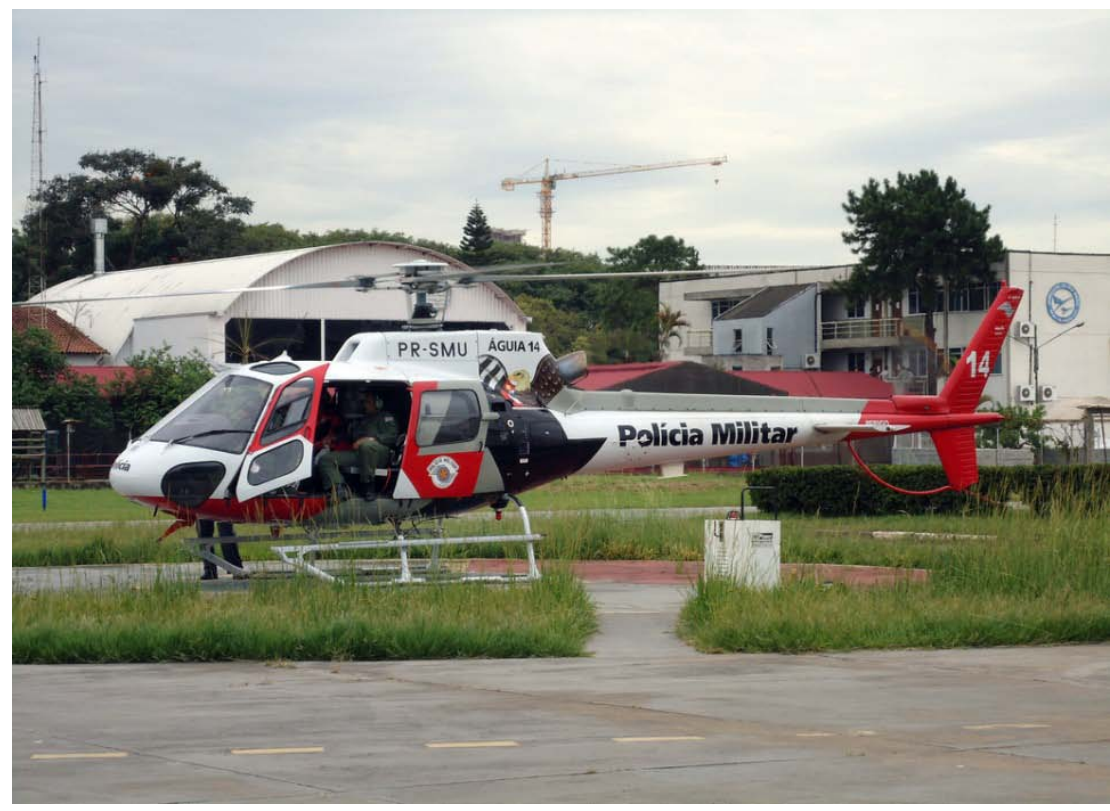

Fig. 1 The AS350-B2 helicopter

There are many flight simulator programs in the market, among which MSFlight Simulator is the most common. Although it is considered as a game, it simulates the helicopter flight and the traffic environment very well [1]. However in computer based flight simulators, there are more important requirements, for example, to supply specific training and to represent faithfully the behaviour of a special helicopter to be used in the instructions and training of new pilots.

Thus, the study of the helicopter flight dynamics becomes mandatory for the project of a helicopter flight simulator.

In the next section, some of the main features of helicopter simulators will be presented, followed by the discussions of some concepts related to helicopter flight dynamics and finally some models of system software engineering developed as well as some representative screens of the final product developed are described. Finally, the conclusions obtained with the development and deployment of the system are presented. 


\section{THE HELICOPTER FLIGHT SIMULATOR}

The necessity of a helicopter flight simulator, for ground school training, depends on human factors and economics, since the more time the pilot pass in the aircraft systems training devices, the better the training quality [2].

Generally the government, companies and institutions that use helicopters train its pilots, initially, in simpler aircraft and, after a number of flight hours, they start to fly as copilots in the aircraft where they will command. The Military Police of São Paulo - PMSP, for example, trains its future pilots in this manner.

The government as the private companies search for economic and safer forms to train its pilots. The training in simulators can decrease the expense to teach a pilot, since schools of helicopter pilot training, charges US\$ 55,000.00 for training a pilot [3]. This value could be decreased with the use of simulators.

Beyond the civil use in the transport of executives, professionals and payload cargo, in Brazil there is a great necessity in defending oil reserves in sea and its borders in the Amazonian forest. Having this in sight, the government has planned a great program to bring up to date and to improve its Armed Forces, planning to buy and to construct equipment for training.

The Helicopter Simulators will be able to bring little expense and more time of training to the pilot in diverse situations, environments and without the risks that can exist during the training

\section{DEVELOPING A LOW COST SIMULATOR}

To represent the helicopter behaviour mathematically, a research work in articles, books and manuals was carried through and some of the results are presented in the next sections $[4,5]$.

\section{A. The Helicopter}

To understand the helicopter behaviour, it is necessary to know its structure in order to analyse the main decisive external and internal factors of its movement: aerodynamic forces and moments, mass properties, engine power, relation referring weight-power and other characteristics.

Based on this knowledge, the mathematical equations for its flight dynamics are detailed. In Fig. 2 the main components of a helicopter can be seen [6].

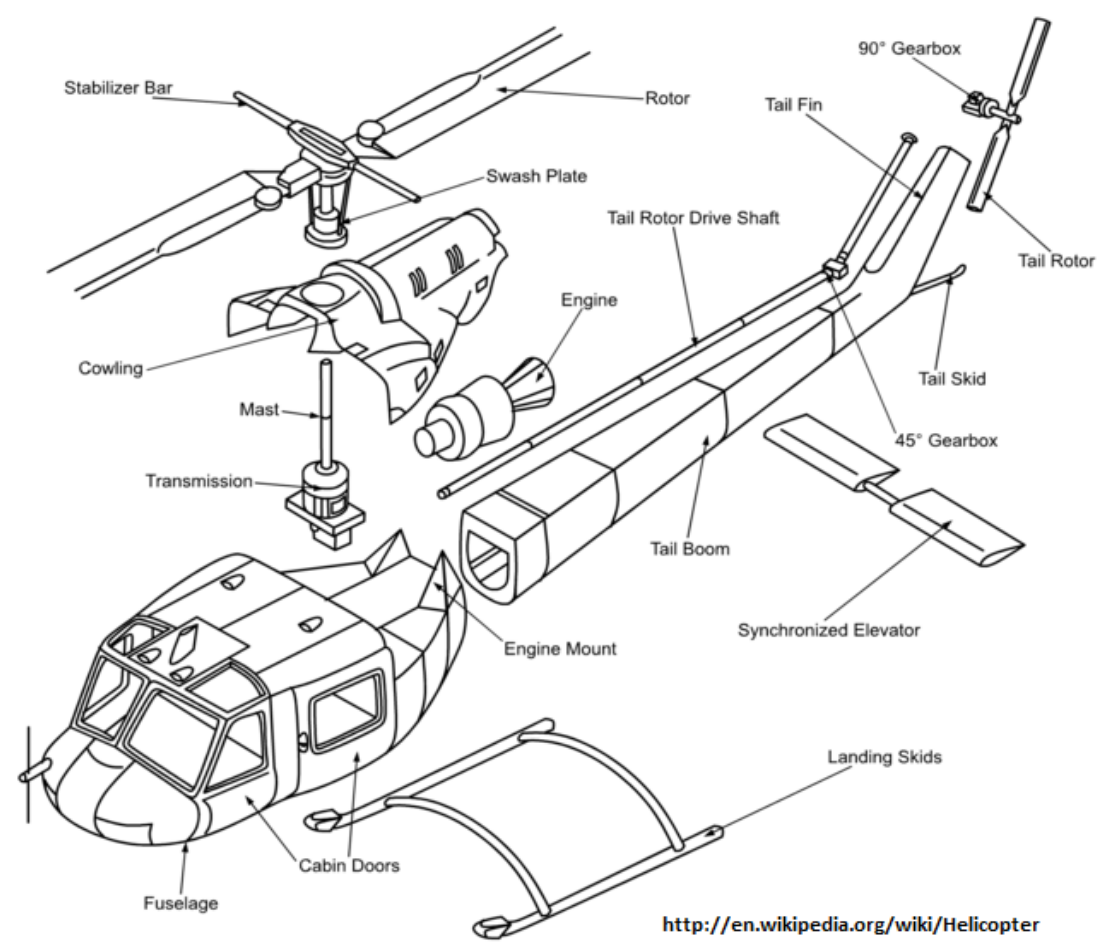

Fig. 2 The helicopter structure

The "Rotor" is the responsible mechanism for keeping the helicopter lift and is composed for the rotating set connected to the rotating set blades connected to the engine. Its control, together with the "swashplate" allows the change of the angle of attack of the rotor blades. This change in the angle makes possible the movement of the helicopter for front, backwards, for the sides and top, as Fig. 3. 


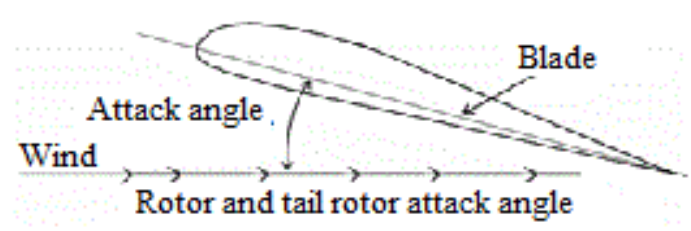

Fig. 3 The rotor characteristic [5]

The "Tail Rotor" is responsible for creating a contrary moment to that one created by torque effect created by the main rotor. It is used to balance the helicopter and also it allows the turn of $360^{\circ}$, [5].

\section{B. Control Equations}

The Helicopter equations of motion written in nonlinear form, according to G. D. Padfield [7], are given by:

$$
\dot{x}=F(\mathbf{x}, \mathbf{u}, t)
$$

Where $\mathrm{F}$ is a nonlinear function of the aircraft motion, $\mathrm{x}$ is the column vector of state variables; $\mathrm{u}$ is the vector of control variables. The state vector is:

$$
x=\{u, w, q, \theta, v, p, \varphi, r, \psi\}
$$

where $\mathbf{u}, \mathbf{v}$ and $\mathbf{w}$ are the translational velocities along the three orthogonal directions of the fuselage fixed axes system; $p, q$ and $r$ are the angular velocities about the $x, y$ and $z$ axes and $\theta, \varphi$ and $\psi$ are the three Euler attitude angles, defining the orientation of the body axes relative to the earth.

The control vector has four components: main rotor collective, longitudinal cyclic, lateral cyclic and tail rotor collective:

$$
x=\left\{\theta_{0}, \theta_{1 s}, \theta_{1 c}, \theta_{0 T}\right\}
$$

where $\theta_{0}$ main rotor collective pitch angle (rad), $\theta_{1 \mathrm{~s}}$ longitudinal cyclic pitch (rad), $\theta_{1 \mathrm{c}}$ lateral cyclic pitch (rad), $\theta_{0 \mathrm{~T}}$ tail rotor collective pitch angle (rad).

Starting from the following non-linearized form the force of equations of motion:

$$
\begin{gathered}
\dot{u}=v r-w q+\frac{X}{M_{a}}-g \sin \theta \\
\dot{v}=w p-u r+\frac{Y}{M_{a}}+g \cos \theta \sin \varphi \\
\dot{w}=u p-v p+\frac{Z}{M_{a}}+g \cos \theta \cos \varphi
\end{gathered}
$$

where $M_{a}$ is the mass of the helicopter and $\mathrm{g}$ is the acceleration due to gravity. The moment equations are:

$$
\begin{gathered}
I_{x x} \dot{p}=\left(I_{y y}-I_{z z}\right) q r+I_{x z}(\dot{r}+p q)+L \\
I_{y y} \dot{q}=\left(I_{z z}-I_{x x}\right) r p+I_{x z}\left(r^{2}-p^{2}\right)+M \\
I_{z z} \dot{r}=\left(I_{x x}-I_{y y}\right) p q+I_{x z}(\dot{p}+q r)+N
\end{gathered}
$$

where $I_{x x}, I_{y y}, I_{z z}$ are the fuselage moments of inertia about the reference axes, $I_{x z}$ is the product of inertia of the helicopter about the $\mathrm{x}$ and $\mathrm{z}$ axes and $\mathrm{L}, \mathrm{M}$ and $\mathrm{N}$ are external aerodynamic moments about the $\mathrm{x}, \mathrm{y}$ and $\mathrm{z}$ axes. The rate of change of three Euler angles:

$$
\begin{gathered}
\dot{\varphi}=\mathrm{p}+\mathrm{q} \sin \varphi \tan \theta+r \cos \varphi \tan \theta \\
\dot{\theta}=\mathrm{q} \cos \varphi-r \sin \varphi \\
\dot{\psi}=\mathrm{q} \sin \varphi \sec \theta+r \cos \varphi \sec \theta
\end{gathered}
$$

All the concepts and equations presented in this section were described in detail by G. D. Padfield in his book Helicopter Flight Dynamics [7] where more detailed descriptions can be found.

Using the characteristic data of aircraft AS350-B2, it is possible to adapt the above equations to this specific model of 
helicopter, supplied by PMSP, and to set into the SDK of the MSFlight Simulator and using the FSUIPC.DLL to supply a feeling very next to the real behaviour of the aircraft in diverse flight conditions.

\section{Modelling the Computer Based System}

According to recent research literature [8] and, despite being a universal concept, the adoption of systems for computer-based training is still often inadequate and inappropriate. However, there are already work in this field [8-10], directed to the training of the various sciences of knowledge.

One of the most recent is the work of students from the Federal University of Itajubá from a course in helicopter flight dynamics offered by a professor from Ecole Nationale de l'Aviation Civile - ENAC, visiting scholar at UNIFEI, where it was developed and implemented a system for interactive helicopter simulation based on computer [10].

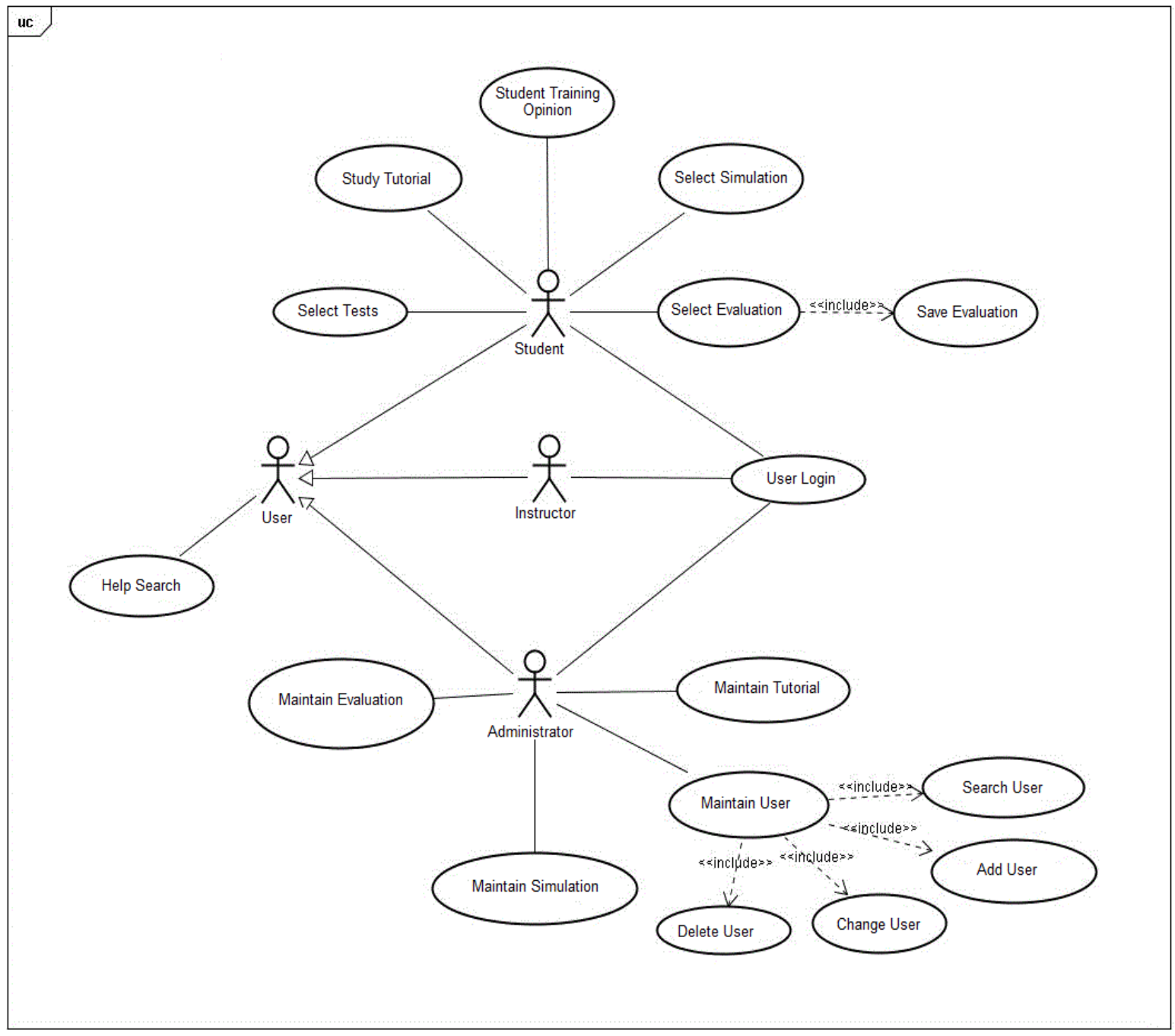

Fig. 4 Use case diagram of the computer based training. Source: authors

The Computer Based Systems have been designed under the basic guidelines to provide students equipment for advanced training based on computers, allowing the practice of the learning activities effectively, and enabling them to carry out their activities in real time. This is performed through familiarization with the various integral components of the matter, considering normal and abnormal situations that are not so improbable.

The software developed with the tutorial serves as a tool for support and guidance of students during the training process. The software is related to the occurrence of events that include drawings, graphics and animation when necessary. The subjects treated in tutorials are in accordance with the manuals provided by the company, and address various issues. Fig. 5 presents the use cases, which explain the interactions of the student and instructor with during the training, including evaluations and simulations. The tutorial has three different kinds of users: the student, the advisor and the administrator.

The UML (Unified Modelling Language) was to model the system, UML is a language completely extensible, adaptable and easy to understand, which uses a graphical notation with a widespread pattern and with different levels of abstraction [10]. 
The tool used to make the modelling is JUDE (Java and UML Developers Environment), created with Java. With the possibility to model complex systems, but it is easy and intuitive to use and present data to the user clearly [11].

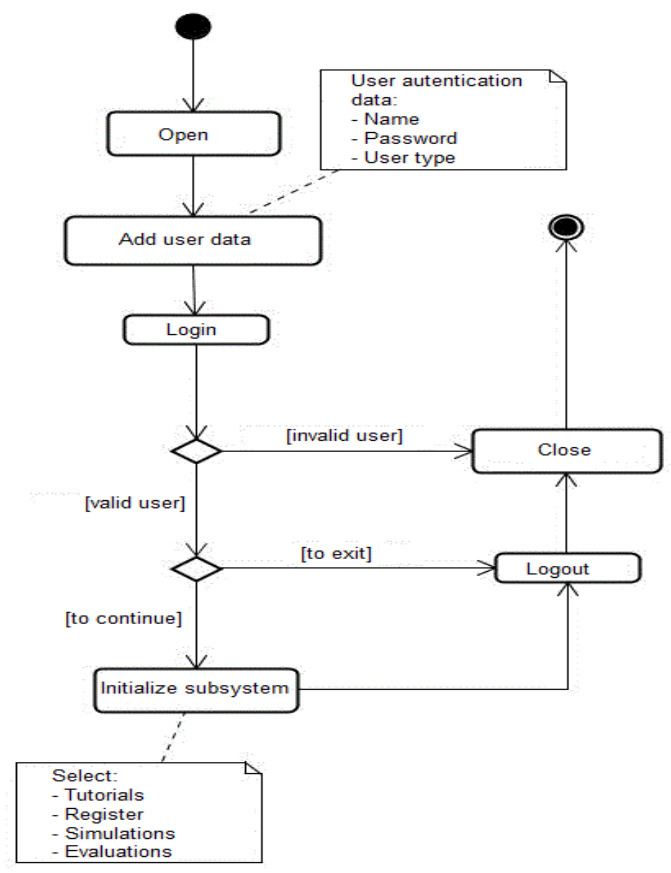

Fig. 5 Activity diagram

The process of conducting software development tutorial, oriented to objects which are complex and are formed by a series of activities for various repetitive elements [12]. Generally the system analysis is based on a high abstraction level, and is designed as follows:

1. The requirements planning and specification must be defined in order to detect the use cases. These are used to obtain the system requirements and creation of scenarios.

2. The construction, which includes two phases:

2.1. The problem analysis, to identify concepts, associations and attributes, and with them, to construct the activity, sequence and state diagrams.

2.2. The problem design, which is used to elaborate the class diagrams to define the system structure.

UML uses activity diagrams to the modeling of dynamic aspects of software, which involves the modeling of sequential steps and/or competitors in each of the subsystems.

The sequence diagram of models for the software is used for the interactions that emphasize the structural organization of the various objects involved in it. Fig. 7 represents the interaction of a user "Student” with the tutorials.

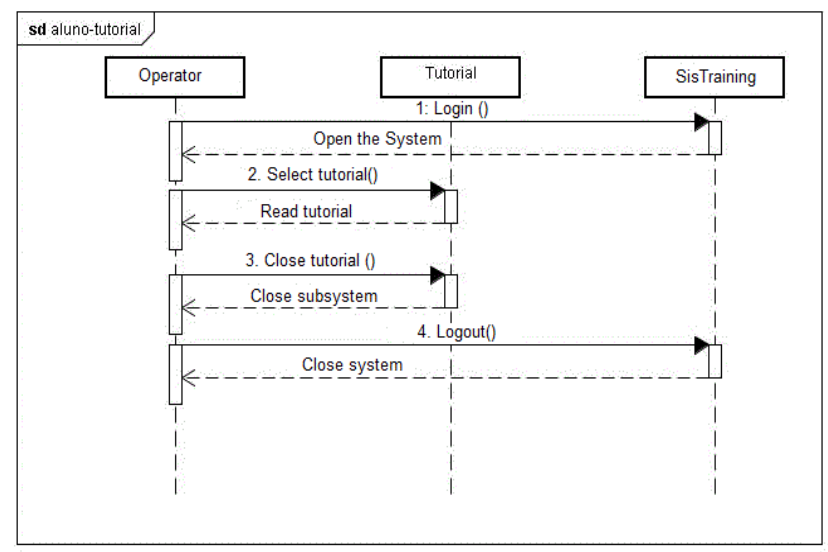

Fig. 6 Sequence diagram 
The class diagram modelled in this paper gives a static view of the software tutorial. The main class of the training system has four classes depending on it (for which you create a relationship of dependency): “Tutorial”, "Register”, “assessment” and "Simulation".

The Class "Tutorial” contains the relationship of generalization with the types of tutorials, which means that each subclass is a kind of tutorial class, as is shown in Fig. 8.

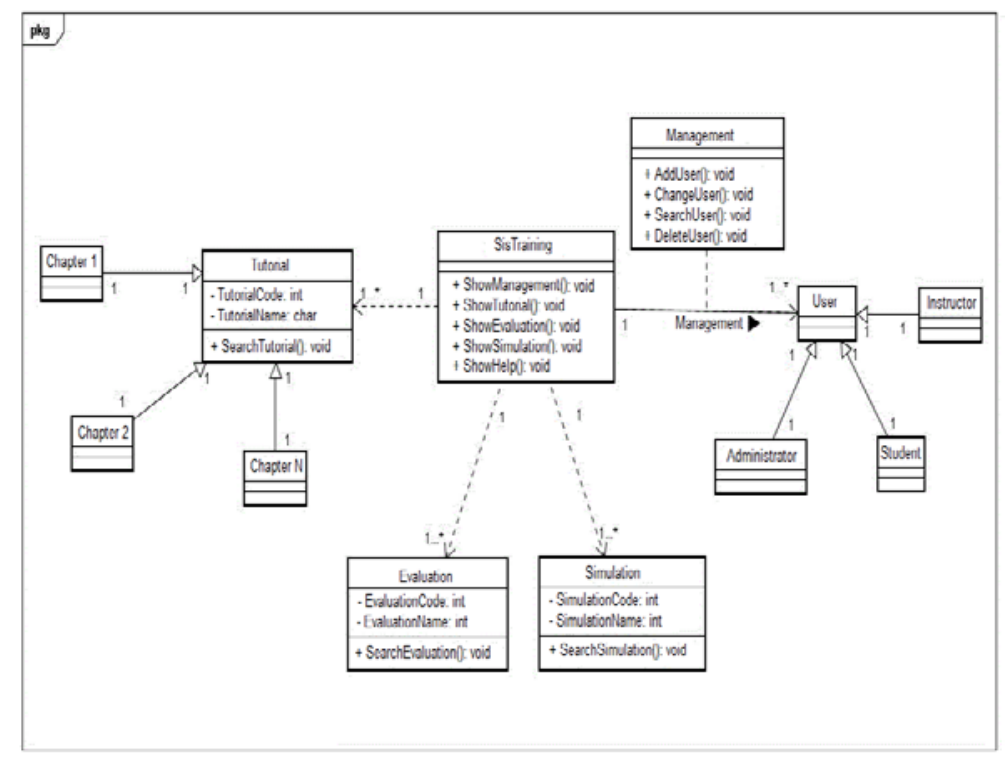

Fig. 7 Class diagram

\section{The Simulator}

Considering the knowledge acquired with the analysis of the helicopter flight dynamics as well as the mathematical study made on the basis of the relative data to the flight instruments, a three modules Pilot Training System was developed:

1. Simulator Module, represents the cabin of the helicopter in scale 1:1 and represents the existing instruments in the AS350-B2 control panel as well as the commands of flight (cyclical, collective, throttle and anti-torque pedals) beyond allowing the pilot, the visualisation of the external scene to the aircraft, as in Fig. 6.

2. Interface Module, using the FSUIPC.DLL extension allows that external programs can communicate and, of limited form until, to control the MSFlight Simulator [8] changing the MSFS systems variables (electrical, hydraulic and fuel) involved in the training

3. Tutorial Module, that presents, in hypermedia format and JAVA language, all the related theories of the flight and functioning of the electrical, fuel and hydraulics systems of the helicopter beyond exercises, tests of knowledge and simulation of normal and abnormal situations that can occur in flight.

The integration of the developed instruments of components in Java language [13, 14], with the MS Flight Simulator suppling the necessary degree of authenticity to the correct representation of the flight [15-17] of AS350-B2, allows the virtual representation of the existing cabin to display instruments in the panel as well as the representation of the external scene from a multimedia projection.

The flight control of the helicopter is made from two joysticks, especially developed and adapted, the cyclical command and the collective command and of the anti-torque pedals for the control of the tail rotor. 


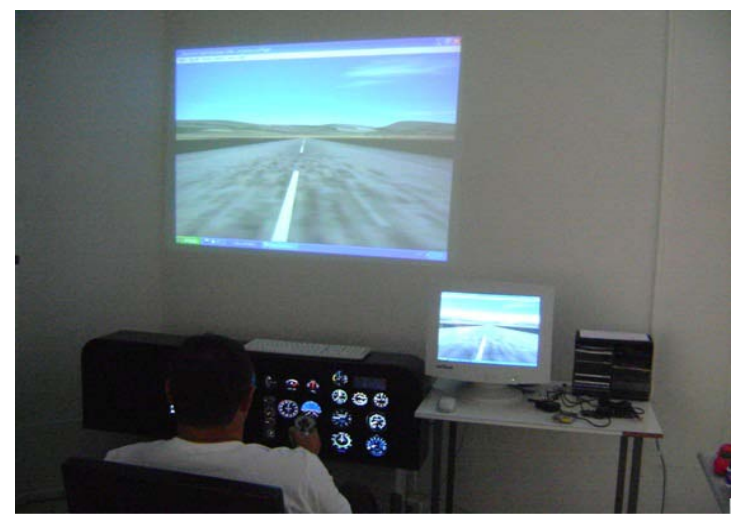

Fig. 8 The low cost flight simulator

The Tutorial Module, as Fig. 9, was developed from existing information found in pilots and maintenance manuals, beyond information supplied for the proper pilots $[18,19]$. The tutorial uses resources of text, presentation of figures of languages JAVA, HTML and representation of animations supplied for the tool Adobe Flash.

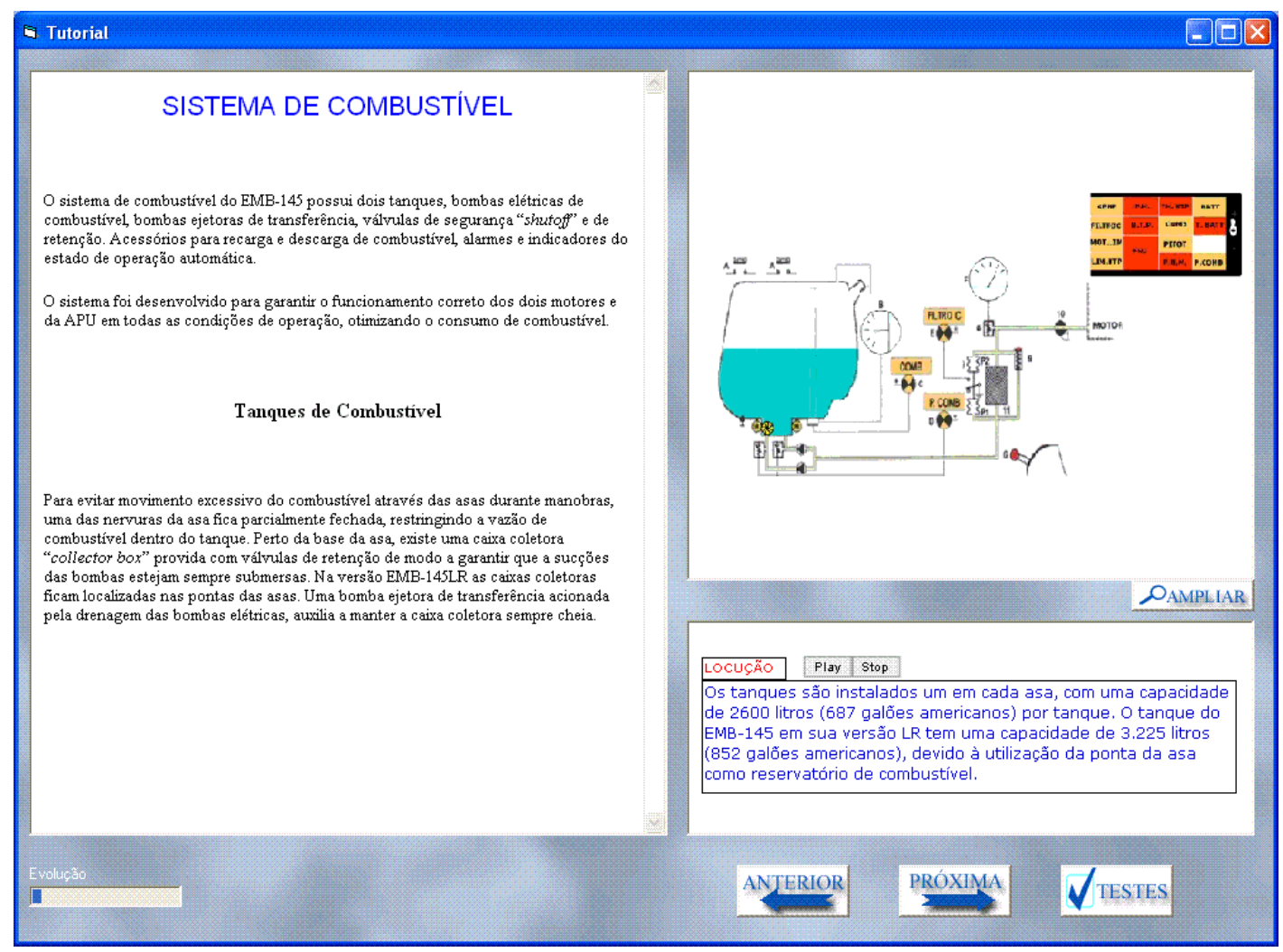

Fig. 9 Print screen of the fuel system tutorial

To verify if the information are easily assimilated, the tutorial account with specific areas for texts with theory and figures regarding what is in study, areas with locutions to strengthen the focus of the studied object, as well as animations presenting the functioning and/or known imperfections that occur in the helicopter subsystems in study. The Tutorial Module must be the first one to be used by the pilot during the training process, and presents the following functionalities:

1. Tutorials on the electrical, hydraulic and fuel systems of the helicopter;

2. Exercises turning on the subjects studied to the end of each chapter of the tutorial;

3. Simulations of emergency situations in which some of the described systems previously contain failures and the helicopter flight conditions are modified;

4. Evaluation and control of the pilot interaction with the simulator, controlling time and instruments used to solve the situations. 


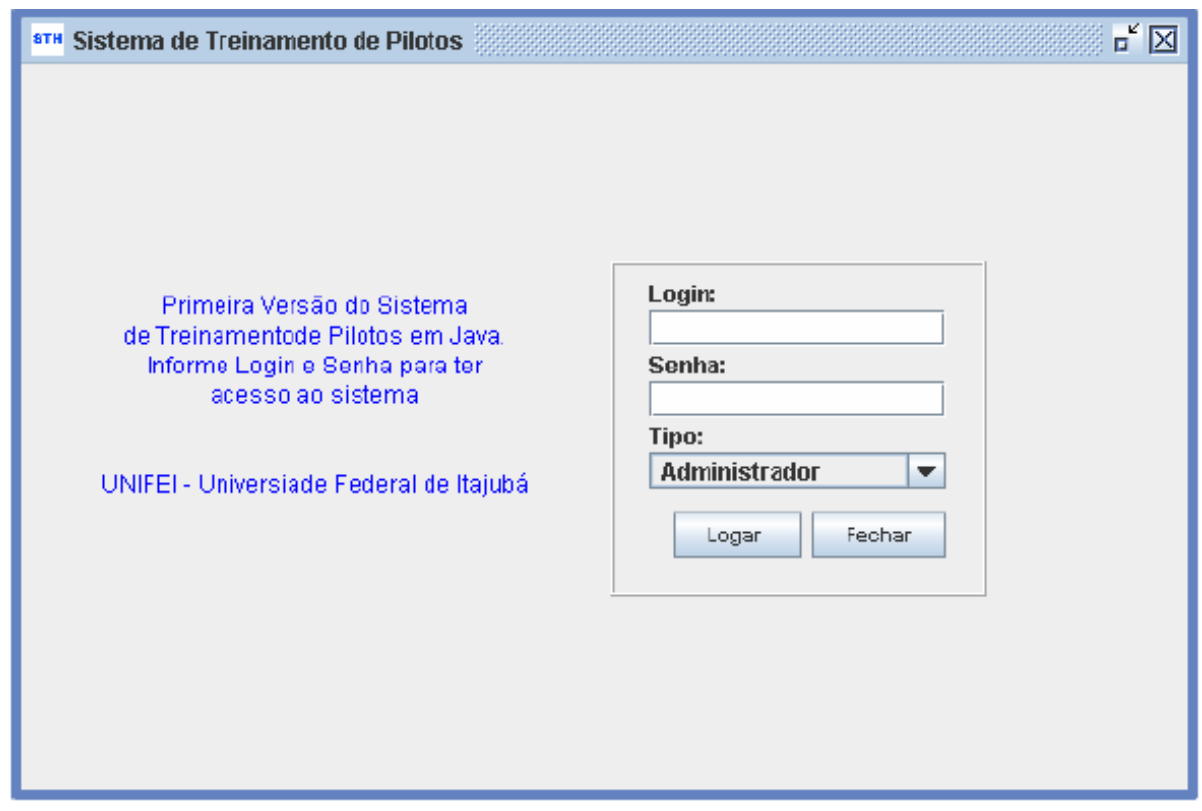

Fig. 10 Print screen of administrator page

All interaction of the student with the tutorial is stored in data base and controlled for a system administrator, as Fig.10, whose main facilities are:

1. Register of users who can be: the proper administrator, a professor (pilot or flight engineer) or a student (pilot in formation or mechanic);

2. Information management, being able to be: tutorial, simulation or animation of flight instruments;

3. Monitoring the evaluations, supplying information of the strong and weak points of each student in relation what it was studied.

\section{CONCLUSIONS}

This article presented simplified helicopter flight dynamic equations, the use of which to simulate a specific helicopter behaviour, the analysis and modelling of low cost Computer Based Training System using UML programming language and the tool JUDE (Java and UML Developer Environment) as well as the system implementation.

The methodology adopted in developing the software tutorial was based on the modelling of the training system, and was presented in the case software developed for the AS350-B2. The plans, specifications of requirements, analysis and design of the system were considered.

That was considered the diagrams to build the model of the system, both with the interaction of the actors found in the analysis, as to their responsibilities and duties. In the current state, the Computer Based System has attracted the interest of some pilot training, and of governmental bodies (Military Police, DETRAN, Armed Forces etc.) that need to train and recycle their pilots.

In accordance with the results already obtained and the referring research to the project that is being carried through currently, the knowledge of the mechanics, mathematics and programming areas have been being used, and a satisfactory final result are predicted, the lack of simulators of this kind can be solved. This flight training system (that includes the flight simulator) being developed has a high cost-benefit, since the pilot can optimize the number of flight hours with real helicopters, running little risks and having an inferior final cost.

\section{ACKNOWLEDGMENTS}

This work has been developed with the support of institutions and companies without which its development would be impossible, therefore the authors would like to be thankful to the Brazilian agencies for research and development FAPEMIG and CNPq for the corresponding financial support the concession of the referring stock markets to the Pilot Training System project, grant FAPEMIG 5.94/08 PA-PG (master science), APQ00305-11 and grant CNPq 507469/2004-6 (Sci\&Tec) and to Aerial Patrol Group from São Paulo state Military, by providing information of the helicopter flight control and operation systems. 


\section{REFERENCES}

[1] R. A. Richards, “Common Cockpit Helicopter Training Simulator,” AVSIM 2002 Stottle Henke Associates, Inc. URL: http://www.stottlerhenke.com/papers/AVSIM_helicopter_cockpit_sim.pdf at 10/01/2014.

[2] K. J. Tintera, Student Pilot Guide, FAA-H-8083-27A, US Department of Transportation. Federal Aviation Administration, 2006.

[3] H. Aviation, Helicopter Profesional Pilot Programs -Program Costs, URL: http://www.hillsboroaviation.com/en/page/helicopter_flight_training_program_costs.

[4] R. Raletz, "Beginner's all-purpose symbolic instruction code theory of helicopter,” Brochure published of Aerospatiale, 1984.

[5] B. Vieira and Serapião, Aerodynamic of helicopters, Ed. River, Rio de Janeiro, 2003.

[6] Brazil Helicopter Company, Manual of instruction for 350 pilots THP B2. Ed, Center of Training of the Brazil Helicopter Company Helicopters of Brasil SA, 2007.

[7] G. D. Padfield, Helicopter Flight Dynamics: The Theory and application of Flying Qualities and Simulation Modelling, Blackwell Publishing Ltd, Second Edition, UK, ISBN 978-14051-1817-0, 2007.

[8] H. Gamboa and A Fred, “Designing Intelligent Tutoring System: A Bayesian Approach,” In: 3rd International Conference on Enterprise Information System, ICEIS’2001, 2001.

[9] S. Kassem, "Documenting electronic commerce systems and software using the unified modeling language,” Information and Software Technology, United Arab Emirates, 2002.

[10] J. R. G. Braga et al, "Modeling system software for computer based training,” proceedings of International conference on Information Technology: New Generations, Las Vegas, 2010.

[11] J. Arlow and I. Neustadt, UML 2 and the unified process: practical object-oriented analysis and design, 2. Ed, Upper Saddle River, NJ: Addison Wesley, 2005.

[12] JUDE - Java and UML Developers’ Environment, In: http://br-linux.org/linux/node/3335/, Access date: Sept. 8, 2007.

[13] J. Rumbaugh, M. Blaha, and W. Premerlani, Modelagem e projetos baseados em objetos, Rio de Janeiro: Campus, 1994.

[14] P. Dowson, "Flight Simulator Inter-Process Communication,” FSUIPC: application interfacing modulates will be MS Flight Simulator, 2008.

[15] F. Lopes, R. L. S. Hisses, and B. C. B. R. Branches, “System of Training of Pilots of Helicopter,” Poster presentation Webmedia 2006.

[16] H. M. Deitel and P. J. Deitel, Java Como Programar, São Paulo: Pearson Education do Brasil, Sexta Edição, p. 1110, 2005.

[17] J. L. Ludwig and H. Jackson, “A common cockpit training system,” I/ITSEC Proceedings, 2001.

[18] J. Burki-Cohen, N. Soja, and T. Longridge, "Simulator Patform Motion - The Need Revisited,” International Journal of Aviation psychology, vol. 8, no. 3, pp. 293-317, 1998.

[19] Wicat Systems, “Comprehensive CBT for Private Pilot, Commercial Pilot, and Air Transport Pilot Training,” URL: http://www.wicat.com/flight/abinitio/wings.htm.

Joice B. Mendes received the B.S. in Computer Science from Federal University of Itajuba - UNIFEI in 2007, and her Master in Systems and Computing Technology of UNIFEI in 2012. She is Information Systems professor at Foundation of Research and Teaching of Itajuba FEPI and has successfully supervised ten (10) graduate students. She is researcher at Multimedia and Interactivity Laboratory - LMI at UNIFEI in the last six years.

Alexandre C. B. Ramos received the B.S. degree in electronic engineering from Faculdade de Engenharia de São José dos Campos, São José dos Campos, Brasil in 1985 and the M.S. and PhD. degrees in Electrical Engineering and Computer Science from Instituto Tecnológico de Aeronáutica, São José dos Campos, in 1992 and 1996, respectively. Since 2003, Mr. Ramos has been working at Universidade Federal de Itajuba and the Multimedia and Interactivity Laboratory for Helibras in the Bio project. His current interests are in intelligent user interface design for eletrical and electronic systems.

Félix Mora-Camino is the head of the Automation Laboratory at ENAC (the french civil aviation institute) in Toulouse where he teaches automatic control and avionics systems design. Once Dr Mora-Camino was a titular professor at COPPE/UFRJ and then a visiting professor at the Royal Air Force Academy of Marrocco in Marrakech. He is doctor in Automatique - Institut National des Sciences Appliquées de Toulouse (1977). 